UDC: $371.3: 811.134 .2 ' 243$

DOI: https://doi.org/10.18485/beoiber.2018.2.1.11

\author{
Mohamed Serfati ${ }^{1}$ \\ Universidad de Las Palmas de Gran Canaria \\ España
}

\title{
EL LÉXICO DISPONIBLE EN ESTUDIANTES MARROQUÍES DE ELE (NIVEL UNIVERSITARIO): INCIDENCIA DE LA VARIABLE "SEXO" $Y$ SU CORRELACIÓN CON EL “CURSO ACADÉMICO”
}

\begin{abstract}
Resumen
El objetivo de este artículo es estudiar el impacto de la variable "sexo" en el léxico disponible de 350 estudiantes marroquíes que aprenden español como lengua extranjera en la Facultad de Letras y Ciencias Humanas de Agadir (Marruecos); que muestran un gran interés por la enseñanza/aprendizaje de este idioma. Tras realizar un breve recorrido por la historia de la disponibilidad léxica, procederemos al análisis de la variable que nos concierne en el conjunto de la muestra para seguir luego con su correlación con el "curso académico". El análisis cuantitativo de los resultados obtenidos nos permite ofrecer datos reveladores sobre la marcada asociación entre disponibilidad léxica y "sexo".

Palabras clave: disponibilidad léxica, español como lengua extranjera, estudiantes marroquíes, productividad léxica, competencia léxica.

\section{THE AVAILABLE LEXICON OF MOROCCAN STUDENTS OF SPANISH (UNIVERSITY LEVEL): INCIDENCE OF THE "SEX GENDER" VARIABLE AND ITS CORRELATION WITH THE "ACADEMIC YEAR"}

Abstract

The objective of this article is to study the impact of the variable "gender" in the available lexicon of 350 Moroccan students who learn Spanish as a foreign language at the Faculty of Letters and Human Sciences of Agadir (Morocco) and who show a great interest in teaching / learning this language. After making a brief tour through the history of lexical availability, we come up with the analysis of the variable that concerns us in the whole of the sample to follow then with its correlation with the "academic course". The quantitative analysis of the results obtained allows us to offer revealing data about the marked association between lexical availability and "gender".

Key words: lexical availability, Spanish as a foreign language, Moroccan students, lexical productivity, lexical competence.

\footnotetext{
1 serfati81@hotmail.com
} 


\section{Introducción}

La disponibilidad léxica es un campo de investigación de la léxico-estadística². Es una herramienta indispensable para la lingüistica como medio para tratar y clasificar rigurosamente los datos que se manejan. Esta disciplina permite determinar cuál es el léxico potencial que un hablante utilizaría en situaciones comunicativas dadas. Este tipo de estudios se inició en Francia ${ }^{3}$, en los años 50 y 60 del siglo pasado, debido al creciente influjo de Estados Unidos y del inglés como un idioma internacional.

El gobierno francés, preocupado por la situación socioeconómica y política del país, vio la necesidad de recuperar el antiguo prestigio mundial potenciando el francés como una lengua de enseñanza y aprendizaje. En ese sentido, se realizaron indagaciones para el establecimiento de un léxico básico para los distintos niveles de enseñanza del francés en los países que pertenecían a la Unión Francesa, donde la lengua francesa era oficial y muy influyente. También, se pretendía facilitar el aprendizaje del francés a los inmigrantes que llegaban a Francia y a extranjeros que por estudios o negocios demandaban aprender el idioma.

Con el objetivo de luchar contra el analfabetismo y la pobreza, se concibió la creación del diccionario Le Français Élémentaire (vid. Gougenheim ${ }^{4}$ et al. 1956), donde se incluyen los términos de mayor uso en la lengua francesa. Para recoger ese léxico elemental del francés, los estudiosos se basaron en la frecuencia de menciones de las palabras aportadas por los sujetos que conforman la muestra, constituida por niños de entre 9 y 12 años. Según Galloso Camacho (2003: 17), Gougenheim pensaba que uuna palabra usual es una palabra frecuente." A su vez, René Michéa (1950), citado por Carcedo González (2001: 12), hizo la distinción entre palabras 'temáticas', que tienen significado léxico cuya frecuencia de aparición depende de los temas tratados en los textos que forman el corpus; y palabras "atemáticas", que carecen de significado léxico ya que se pueden encontrar en cualquier tipo de texto, con independencia de su contenido.

2 Permite analizar la adquisición léxica, la riqueza léxica o recabar el léxico básico y el disponible. Nos ayuda a cuantificar las formas léxicas que utiliza una determinada comunidad de habla y al mismo tiempo nos da información sobre la cantidad necesaria de ejercicios para enriquecer el potencial léxico de los hablantes. Ya que los recuentos léxicos permiten construir y confeccionar los diccionarios de una lengua partiendo del cómputo de todas las palabras y vocablos que aparecen en un corpus, bien sea oral o escrito. La aplicación de los métodos de la léxico-estadística ha dado lugar a valiosos estudios: López Chávez et al. (1993), Alba Ovalle (1995), Samper Padilla y Hernández Cabrera (1997), Mateo García (1998), Valencia y Echeverría (1999), Prado Aragonés y Galloso Camacho (2005), entre otros autores.

3 Según Samper Hernández (2002: 8), la historia de la disponibilidad léxica la podemos dividir en dos grandes apartados, unidos por un nexo estrecho: por un lado, tendríamos las aportaciones que realizan Michéa, Gougenheim, Rivenc y Sauvageot en los años 50 y 60, y, por otro, las que se han llevado a cabo en los últimos años, especialmente en el mundo hispánico.

${ }_{4}^{4}$ Gougenheim trabajó con escolares de 9 a 12 años (vid. Gómez Molina y Gómez Devís 2004: 12). 
Es así como, la disponibilidad léxica llegó a ser un complemento relevante para los diccionarios de frecuencias (vid. Samper Padilla et al. 2003: 30).

Los primeros estudios de disponibilidad léxica en el español datan de la década de los 70 y se concentran en el área caribeña. En Puerto Rico ${ }^{5}$. Humberto López Morales ha sobresalido en este campo investigativo y se ha encargado de su difusión y desarrollo 6 . Se ha interesado por el establecimiento y perfeccionamiento de la fórmula para calcular el índice de la disponibilidad léxica (considerando la frecuencia de aparición de las palabras y las posiciones que ocupan en los listados (vid. Benítez Pérez 1992a: 78)).

Actualmente, López Morales coordina un proyecto panhispánico, denominado Proyecto de Estudio de la Disponibilidad Léxica en Español (PPHDL), para conocer la norma léxica del español a partir del léxico disponible de estudiantes preuniversitarios ${ }^{7}$. El principal objetivo de este proyecto es elaborar diccionarios de disponibilidad léxica para las diversas zonas del mundo hispanoparlante, que servirán de base para la comparación léxica, etnográfica y cultural (vid. Gómez Molina y Gómez Devís 2004: 14).

En cuanto al español como lengua extranjera, desde los inicios de este nuevo siglo, se están incrementando los trabajos sobre la disponibilidad léxica de estudiantes de español como Lengua Extranjera. Las primeras investigaciones en este ámbito fueron llevadas a cabo, fundamentalmente, por Carcedo González (2000a), con estudiantes finlandeses de enseñanza media, y Samper Hernández (2002), con extranjeros universitarios en la ciudad de Salamanca (España). Dichos estudios tenían como objetivo principal conocer el vocabulario que debía incluirse en los manuales para la enseñanza de la lengua.

En este artículo nos centraremos de forma exclusiva en el análisis del condicionante "curso académico" y su correlación con el factor "sexo", para el que se seleccionan dos grupos representativos, con la finalidad de comprobar si se mantienen las diferencias en su léxico disponible, se incrementan o disminuyen entre nuestros informantes.

5 El primer trabajo que trataba sobre las variables sociales que intervenían en el desarrollo de adquisición léxica en los escolares de primer grado Frecuencia y disponibilidad léxica en escolares de primer grado. Según Samper Padilla et al. (2003: 31), este estudio nunca llegó a publicarse.

6 Los primeros pasos dados por López Morales en San Juan de Puerto Rico fructificaron tanto en España como en Hispanoamérica.

7 Esto responde al deseo de contar con informantes no universitarios puesto que las investigaciones del proyecto panhispánico pretenden para describir la norma léxica disponible contar con alumnos preuniversitarios que no manejen una variedad de lengua especializada por razones de trabajo o de estudios (vid. Samper Padilla et al. 2003: 65). Nosotros, sin embargo, hemos querido que los encuestados fuesen aprendientes supuestamente mentalizados del interés que tiene el respeto a la norma lingüística en el desarrollo de sus trayectorias universitarias y profesionales. 


\section{Metodología}

\subsection{La muestra}

Al tratarse de una investigación de gran envergadura, teniendo en cuenta las dimensiones territoriales del país, y al no ser posible obtener un grupo de estudio representativo para cada zona que pudiera abarcar todos los objetivos, se decidió reducir la envergadura del proyecto, y así centrarse en la Universidad Ibn Zohr de Agadir, que cubre toda la zona del Sur marroquí. Con esto encuestamos a 350 estudiantes universitarios que en el curso 2013-2014 estudiaban español como lengua extranjera en el Departamento de Hispánicas de la Facultad de Letras y Ciencias Humanas de la Universidad Ibn Zohr de Agadir ${ }^{8}$. Veámoslo

\begin{tabular}{|c|c|c|}
\cline { 2 - 3 } \multicolumn{1}{c|}{} & Número de informantes & Porcentajes \% \\
\hline Hombres & 131 & 37 \\
\hline Mujeres & 219 & 63 \\
\hline
\end{tabular}

Cuadro 1. Distribución de la muestra según la variable "sexo"

Como puede observarse, hay una clara superioridad del sexo femenino. En la muestra que nos incumbe, tenemos a 219 mujeres (63\%), frente a 131 hombres (37\%). Esto es explicable, últimamente, porque los hombres tienden más que las mujeres a realizar solo estudios primarios y secundarios, puesto que se incorporan al mundo laboral a edades más tempranas que las mujeres, sobre todo en familias paupérrimas cuyos hijos descienden de padres desfavorecidos e incultos, que ven en los varones una fuente de ingresos para la familia: deciden no terminar sus estudios en niveles superiores en comparación con las mujeres que sí los hacen. El gráfico que insertamos, a continuación, lo esclarece perfectamente.

${ }^{8}$ Con nuestro trabajo pretendemos extender los estudios de disponibilidad léxica a otros grupos sociales con características muy distintas de la población escolar de la enseñanza media. Para ello, hemos recogido el léxico disponible de 350 estudiantes universitarios en la Facultad de Letras y Ciencias Humanas de la Universidad Ibn Zohr de Agadir, Marruecos. 
Distribución de la muestra según la variable 'sexo'

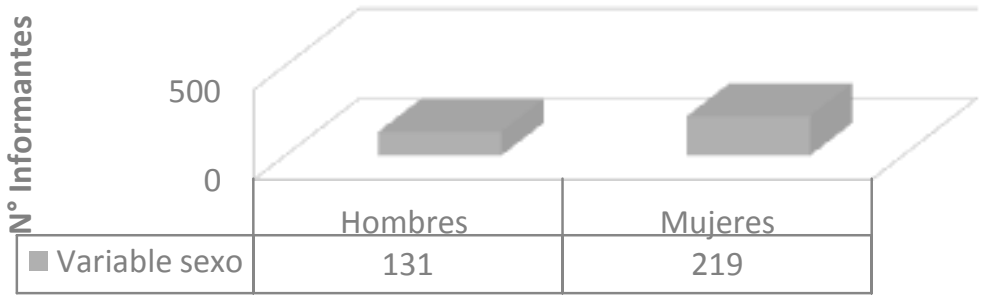

\section{Gráfico 1}

Comparando porcentualmente la muestra por sexos, observamos que el porcentaje de mujeres (63\%) presente en la muestra es superior a los hombres (37\%). Esta presencia mayor de mujeres que de hombres en las aulas se observa últimamente tanto en los estudios realizados con encuestados preuniversitarios ${ }^{9}$ hispanoparlantes como en los llevados a cabo con informantes extranjeros. Es lo que reflejan los tamaños en las distintas indagaciones sobre el léxico disponible que se han realizado en varias sintopías. Por una parte, reconocen influencia de este condicionante, inclinándose hacia el femenino: Echeverría (1987) en Chile; Alba Ovalle (1995) en la República Dominicana; Samper Padilla y Hernández Cabrera (1997) en Las Palmas de Cran Canaria; Bartol Hernández (2004) en Soria; Ayora Esteban (2007) en Ceuta y Prado Aragonés y Galloso Camacho (2008) en Huelva.

Por otra parte, en informantes de ELE que han utilizado un procedimiento aleatorio en la selección de su muestra destacan los estudios de Carcedo Conzález (2000a): 295 mujeres y 55 hombres; Samper Hernández (2002): 28 mujeres y 17 hombres; Sandu (2014): 204 mujeres y 76 hombres, entre otros autores. La única excepción a esta distribución a favor de los hombres es nuestra investigación (vid. Serfati 2010), llevada a cabo en la Facultad de Letras y Ciencias Humanas de Agadir, que cuenta con 17 mujeres y 23 hombres y también el trabajo realizado por Pérez Serrano (2009),

9 No obstante, en las investigaciones de López Morales (1979) en Puerto Rico; Benítez Pérez (1992a) en Madrid; García Megía (2003) en Almería; Samper Hernández (2003) en Gran Canaria; Bellón Fernández (2003) en Córdoba y Serfati (2010) en Agadir (Marruecos), la ventaja se muestra a favor de los hombres. Merced a estas discrepancias, se ha utilizado, últimamente, un programa similar al 'Lexidisp' llamado 'SPSS' para ver si estas diferencias detectadas eran de origen casual o se debían a factores meramente sociales. A pesar de todo, no se llegó a resultados convincentes (vid. los trabajos de Gómez Molina y Gómez Devís 2004: 94) que llevaran a una clara ventaja de las mujeres sobre los hombres en todos los centros de interés, conclusión que coincide aparentemente con el estudio realizado por Samper Padilla y Hernández Cabrera (1997); también el trabajo de Galloso Camacho (2003: 92) en el que detectó una ligera ventaja a favor de los hombres en Salamanca y Zamora a cambio de una sutil igualación entre ambos sexos en Ávila. 
aunque esta última investigadora trabaja solamente con dos campos nocionales: 12 "Medios de transporte" y 16 "Profesiones y oficios".

Porcentaje de hombres y mujeres según la variable 'sexo'

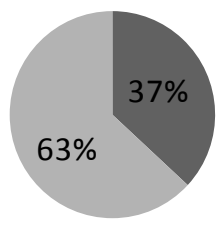

Hombres

Mujeres

\section{Gráfico 2}

Para el estudio de la incidencia del factor "sexo" y su correlación con el "curso académico" en el léxico disponible de nuestros informantes, hemos tenido en cuenta la distribución de hombres y mujeres según el condicionante "curso académico". El resultado es el que indica el cuadro siguiente:

\begin{tabular}{|l|c|c|c|c|c|c|}
\cline { 2 - 7 } \multicolumn{1}{c|}{} & \multicolumn{2}{c|}{ Curso 1 } & \multicolumn{2}{c|}{ Curso 2 } & \multicolumn{2}{c|}{ Curso 3 } \\
\cline { 2 - 7 } \multicolumn{1}{c|}{} & Núm. & $\%$ & Núm. & $\%$ & Núm. & $\%$ \\
\hline Hombres & 43 & 30 & 31 & 32 & 57 & 51 \\
\hline Mujeres & 99 & 70 & 65 & 68 & 55 & 49 \\
\hline Total & 142 & 100 & 96 & 100 & 112 & 100 \\
\hline
\end{tabular}

Cuadro 2. Distribución de la muestra según la variable "sexo" por "curso académico"

Distribución de la muestra según la variable 'sexo' por 'curso académico'

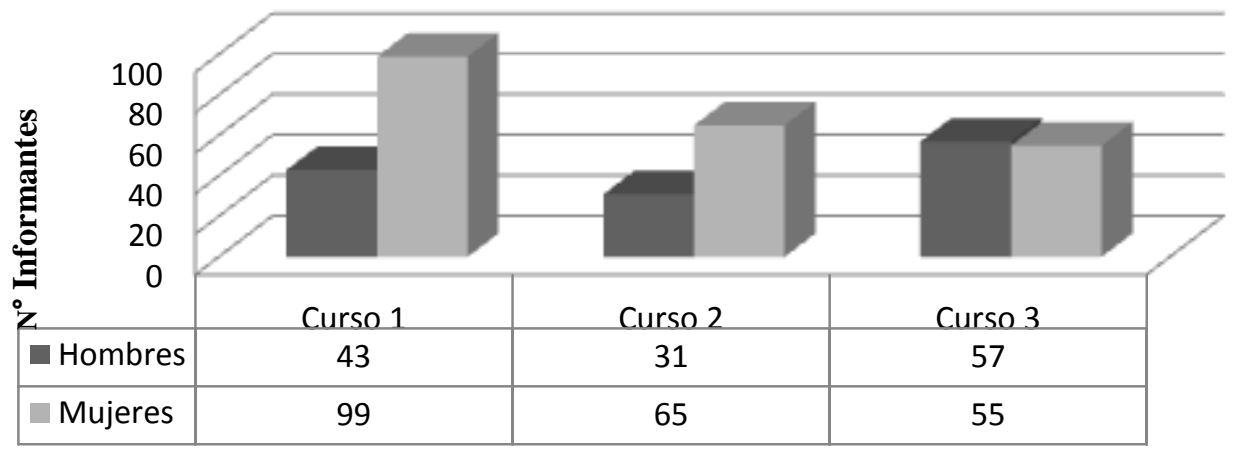

Gráfico 3 
Porcentaje de hombres y mujeres: Curso 1

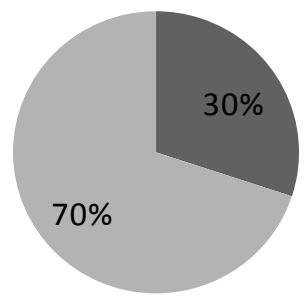

- Hombres

Mujeres

Gráfico 4

Porcentaje de hombres y mujeres: Curso 2

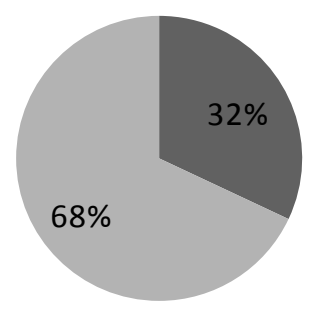

\section{Gráfico 5}

Porcentaje de hombres y mujeres: Curso 3

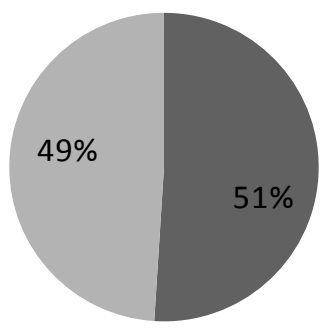

\section{Gráfico 6}




\subsection{La encuesta ${ }^{10}$}

Es experimental, se aplican pruebas asociativas escritas, generalmente a estudiantes, en las que se emplean temas o centros de interés como estímulos para la obtención de respuestas. En las primeras pruebas de disponibilidad léxica los encuestados debían completar listas cerradas, con 20 palabras en cada centro de interés, con un tiempo máximo de 15 minutos (vid. Gougenheim, Michéa, Rivénc, Sauvageot 1964; Mackey 1971). Luego, este tiempo se ha reducido hasta los 5 minutos y hoy en día a 2 minutos por cada centro de interés"

De acuerdo con esto, en el presente estudio, trabajamos con listas abiertas (vid. Dimitríjevic 1969) y con tiempo de reacción de 2 minutos para cada centro de interés; como bien observa Samper Hernández (2002: 21) "dos minutos era un tiempo suficiente para escribir bastantes unidades e incluso para bucear en su memoria en busca de alguna más". De esta forma, se pueden obtener resultados tanto cuantitativos como cualitativos. En nuestro estudio, hubo algunos informantes universitarios que terminaron antes del tiempo límite y no tenían más vocablos que aportar.

La encuesta que se entregó a cada universitario está compuesta por dos partes muy diferenciadas. La primera parte debía ser rellenada por el informante con sus datos personales, profesionales y académicos. Todo ello nos proporciona información relevante para la composición de las variables. La segunda parte sigue el modelo panhispánico, que consta de diecisiete centros de interés. Se mantienen las columnas con la cabecera y un total de 27 líneas numeradas por folio para que cada encuestado redacte sus respuestas. Tal decisión está de acuerdo con lo que menciona la profesora Samper Hernández (2002: 21) “la organización en columnas con líneas enumeradas posibilita que se pueda tener en cuenta la posición de la palabra dentro del número total de respuestas de cada encuesta". De este modo, el léxico disponible de los estudiantes marroquíes de nivel universitario empezó a recogerse a partir de unos centros de interés que actuaban como estímulos verbales que - aunque modificados en otros estudios en función de las características propias de la comunidad estudiada - se siguen utilizando hoy en día en todos los trabajos que forman parte del magno Proyecto Panhispánico de Disponibilidad Léxica (PPHDL).

10 Sigue el mismo modelo del Proyecto Panhispánico de Disponibilidad Léxica (PPHDL), que se está realizando en España e Hispanoamérica, bajo la dirección de López Morales. Los materiales obtenidos constituyen instrumentos de primera mano para conocer las habilidades de escritura u orales de los encuestados, para poder planificar la fórmula del léxico disponible y obtener índices confiables que permiten conseguir materiales de estudio.

${ }^{11}$ Aunque las soluciones eran muy diversas en cuanto al tiempo de respuesta: desde los cinco minutos que conceden Dimitríjevic (1969) y Ruiz Basto (1987), pasando por los tres minutos de López Chávez (1994), a los dos minutos que utilizó Mena Osorio (1986) ya que es el tiempo que se ha impuesto como pauta general en el Proyecto Panhispánico de Disponibilidad Léxica (PPHDL). La única autora que no ha tomado en cuenta el tiempo ha sido Justo Hernández (1986), que estableció un cupo máximo de diez unidades léxicas, ya que lo que le preocupaba era el número de palabras (cf. Benítez Pérez 1992b). 
Entre los centros de interés que hemos tomado en consideración en nuestra investigación destacan, especialmente, los siguientes: 1) "Partes del cuerpo", 2) "La ropa", 3) "Partes de la casa (sin muebles)", 4) "Los muebles de la casa", 5) "Alimentos y bebidas", 6) "Objetos colocados en la mesa para la comida", 7) "La cocina y sus utensilios", 8) "La escuela: muebles y materiales", 9) "lluminación, calefacción y medios de airear un recinto", 10) "La ciudad", 11) “El campo", 12) “Medios de transporte", 13) “Trabajos del campo y del jardín”, 14) “Los animales”, 15) “Juegos y distracciones”, 16) "Profesiones y oficios", 17) "Los colores"2". Estos marcos temáticos son perfectamente válidos para nuestro estudio, si bien la clasificación propuesta está abierta a la incorporación de nuevos campos léxicos, si así lo requieren las necesidades de adaptación a ciertas realidades culturales (vid. Carcedo González 2000b: 178-182; Samper Hernández 2002: 21-22).

\section{Criterios de edición}

Para la edición de los materiales obtenidos en nuestro trabajo y su volcado en el programa LexiDisp ${ }^{13}$ (vid. Serfati 2017: 111-117), se han seguido las directrices elaboradas por el profesor Samper Padilla (1998) y posteriormente presentadas en las reuniones de Bilbao (1999) y de San Millán de la Cogolla (2003). Estas pautas son las siguientes: se han puesto criterios comunes para la limpieza de los listados. Esta etapa de investigación ha sido compleja, pues en ella se manifiesta la interferencia de la lengua materna. Samper Hernández (2002: 22), la define como la limpieza de los materiales, porque implica percibir los problemas como la unificación de las distintas variables léxicas y sus asociaciones, etc. La decisión del investigador puede ser decisiva y requiere mucho cuidado. Por todo ello, hemos seguido las pautas del profesor Samper Padilla (1998), con las precisiones que nos exigía el vocabulario recogido: este trabajo sirve de ayuda a los investigadores que se enfrentan a las mismas decisiones a la hora de editar el léxico disponible.

12 Hemos añadido este centro de interés a la lista de 16 centros clásicos con fines investigadores concretos, tal como han hacho distintos estudiosos dentro del Proyecto Panhispánico (vid. Benítez Pérez 1992b; Samper Padilla y Hernández Cabrera 1995; Etxebarría Arostegui 1996; Mateo García, 1998; Ayora Esteban 2003; Arnal Purroy et al. 2004; Gómez Devís 2004; Prado Aragonés y Galloso Camacho 2005; Ahumada Lara 2006; Casanova Ávalos 2006), entre otros autores.

${ }_{13}$ Un programa informático para el cálculo de la disponibilidad léxica, con el fin de ponerlo al servicio de los investigadores a nivel internacional. 


\section{Resultados y discusión}

\subsection{El "sexo" y su correlación con la variable "curso académico"}

\subsubsection{Producción de palabras}

La mayor producción léxica de los hombres según el condicionante "sexo" en los datos generales sigue permaneciendo al analizar esta variable en cada curso universitario, salvo en el tercer curso donde la diferencia no supera un punto de promedio a favor de las mujeres $(0,91)$. Por tanto, la correlación de estos dos factores nos permite observar que la distancia entre hombres y mujeres entre los dos primeros cursos cotejados se mantiene prácticamente igual $(0,83$ y 0,74 , respectivamente) .

De la misma forma, vemos que los hombres del último curso de formación universitaria muestran un leve retroceso con relación a los cursos anteriores $(-0,79,-1,69$, respectivamente), lo que podría explicarse supuestamente por el estancamiento en la producción léxica en esta fase universitaria; mientras que las mujeres del mismo curso registran un aumento de un 0,86 y 0,05, respectivamente. Este es un dato de gran interés para los docentes, pues muestra claramente no solamente la merma producción léxica de los informantes en todas las fases educativas, sino también un retroceso acusado en el subconjunto que constituyen los informantes del tercer curso, por lo que no ha sido corroborada nuestra hipótesis inicial que suponía que a medida que aumenta el curso académico también incrementa la productividad léxica.

\begin{tabular}{|c|c|c|c|c|c|c|}
\cline { 2 - 7 } \multicolumn{1}{c|}{} & \multicolumn{3}{c|}{ Correlación de variables: “sexo" y “curso académico" } \\
\cline { 2 - 7 } \multicolumn{1}{c|}{ Curso 1 } & \multicolumn{2}{c|}{ Curso 2 } & \multicolumn{2}{c|}{ Curso 3 } \\
\hline C.114 & Hombre & Mujer & Hombre & Mujer & Hombre & Mujer \\
\hline 01 & 11,13 & 10,37 & 12,70 & 11,69 & 11,96 & 11,61 \\
\hline 02 & 7,39 & 6,60 & 7,19 & 6,36 & 6,28 & 6,4 \\
\hline 03 & 8,30 & 7,78 & 8,45 & 7,78 & 8,28 & 8,83 \\
\hline 04 & 8,65 & 7,75 & 8,03 & 8,01 & 5,52 & 6,18 \\
\hline 05 & 9,53 & 9,44 & 9,45 & 8,2 & 8,98 & 10,03 \\
\hline 06 & 5,37 & 5,25 & 4,90 & 4,89 & 5,40 & 13,4 \\
\hline 07 & 6,23 & 6,19 & 5,83 & 6,29 & 5,45 & 6 \\
\hline 08 & 11,25 & 11,01 & 8,58 & 9,10 & 8,84 & 9,56 \\
\hline 09 & 5,39 & 4,78 & 4,58 & 4,10 & 4,84 & 5,52 \\
\hline
\end{tabular}

${ }^{14}$ A partir de este momento utilizamos los números para determinar los nombres de los centros de interés, cuyo listado ya incluimos en páginas anteriores. 


\begin{tabular}{|c|c|c|c|c|c|c|}
\hline 10 & 12,48 & 11,53 & 11,64 & 10,21 & 10,40 & 11,12 \\
\hline 11 & 10,39 & 9,82 & 8,80 & 7,12 & 7,92 & 7,94 \\
\hline 12 & 9,18 & 7 & 8,22 & 7,01 & 7,82 & 6,92 \\
\hline 13 & 6,53 & 5,66 & 6,94 & 5,73 & 5,84 & 6,41 \\
\hline 14 & 11,80 & 10,85 & 11,03 & 10,32 & 8,87 & 9,70 \\
\hline 15 & 10,18 & 7,19 & 7 & 5,50 & 6,22 & 5,67 \\
\hline 16 & 16,16 & 14,28 & 12,61 & 10,89 & 10,77 & 12,50 \\
\hline 17 & 9,41 & 9,64 & 8,19 & 8,15 & 7,14 & 8,14 \\
\hline Media & 9,37 & $\mathbf{8 , 5 4}$ & $\mathbf{8 , 4 7}$ & $\mathbf{7 , 7 3}$ & $\mathbf{7 , 6 8}$ & $\mathbf{8 , 5 9}$ \\
\hline
\end{tabular}

Cuadro 3. Promedio de respuestas según la correlación de variables: "sexo" y "curso académico"

Correlación de variables 'sexo' y 'curso académico' según el promedio de respuestas

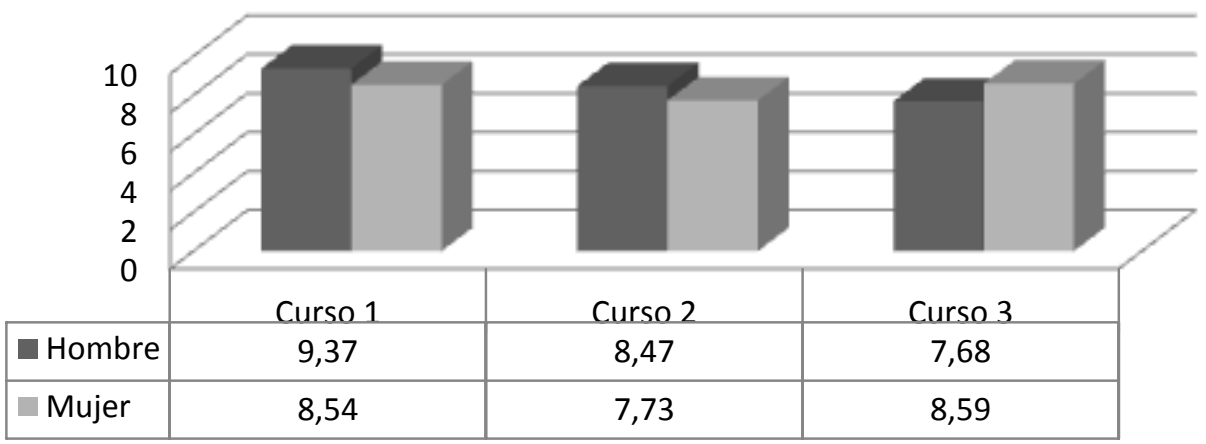

Gráfico 7 
Correlación de las variables 'curso 1' y 'sexo' según el promedio de respuestas de cada centro de interés

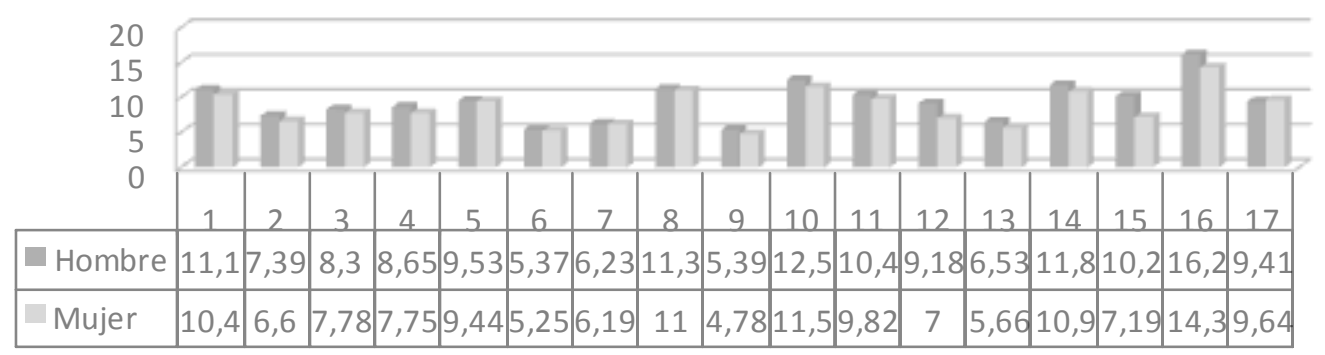

\section{Gráfico 8}

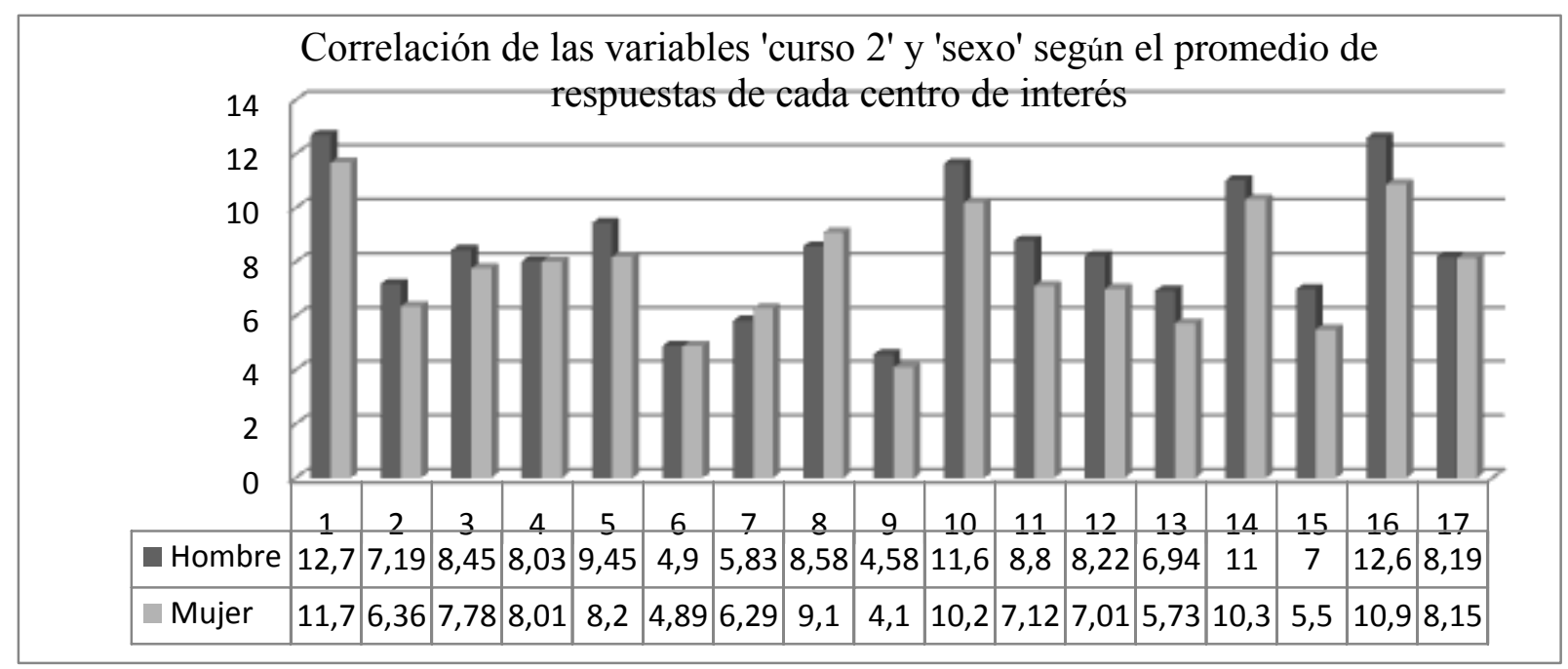

\section{Gráfico 9}

Correlación de las variables 'curso 3' y 'sexo' según el promedio de respuestas de cada centro de interés

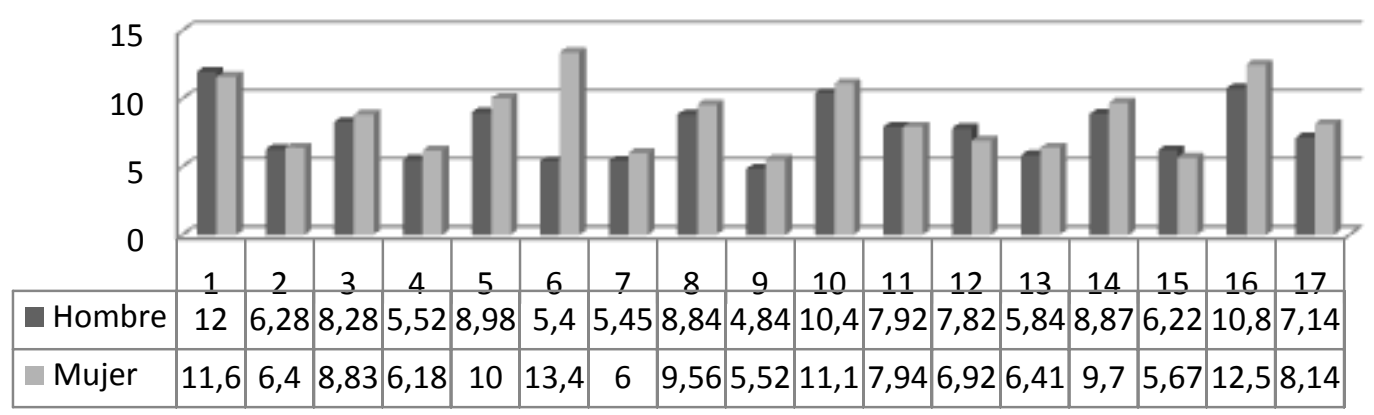

\section{Gráfico 10}

BEOIBERÍSTICA Vol. II / Número 1 (2018) | 153-180 
Asimismo, sobresale el hecho de que los hombres del primer curso universitario incorporen más unidades léxicas que los informantes del último curso $(9,37 ; 7,68$, respectivamente), con un 1,69 puntos de promedio. Por el contrario, esta diferencia no supera, como hemos dicho, un 0,05 de promedio a favor de las mujeres del último curso de formación universitaria.

Si nos atenemos a la evolución entre hombres y mujeres en cada curso universitario por centro de interés, nos damos cuenta de que a medida que se avanza en el nivel de estudios en los dos primeros cursos académicos, encontramos una evolución regular de los centros de interés 01 "Partes del cuerpo", 03 "Partes de la casa (sin muebles)" y 13 "Trabajos del campo y del jardín" entre hombres; mientras que los centros de interés 01 "Partes del cuerpo", 04 "Los muebles de la casa", 07 "La cocina y sus utensilios", 12 "Medios de transporte" y 13 "Trabajos del campo y del jardín" figuran entre las mujeres de ambos grupos que registran una sutil diferencia.

En cambio, vemos que los ámbitos nocionales que más incremento manifiestan entre ambos extremos de la tabla, es decir, entre los informantes del primer y último curso universitario, encontramos los campos léxicos 01 "Partes del cuerpo" y 06 "Objetos colocados en la mesa para la comida" entre hombres y 01 "Partes del cuerpo", 03 "Partes de la casa (sin muebles)", 05 "Alimentos y bebidas", 06 "Objetos colocados en la mesa para la comida" y 09 "Iluminación, calefacción y medios de airear un recinto" entre mujeres. Por otro lado, a medida que aumenta el curso académico, llama nuestra atención el descenso mostrado en la productividad léxica registrado por las medias de cada curso por separado entre los hombres; mientras que en las mujeres de ambos extremos de la tabla se produce un leve aumento, con un decrecimiento notable de apenas un punto de promedio en el segundo curso $(0,81)$.

En el cuadro 4, que viene a continuación, se recoge el rango asociativo de cada ámbito temático en los diferentes grupos de informantes que componen la muestra en función del condicionante "sexo" y su correlación con la variable “curso académico". Como puede observarse, hay una similitud en la posición relativa de los campos más rezagados: 09 "Iluminación, calefacción y medios de airear un recinto" ocupa prácticamente el mismo rango en todas las columnas excepto en la primera referente a los hombres del primer curso, donde alcanza el decimosexto lugar; también el campo asociativo 06 "Objetos colocados en la mesa para la comida" - el segundo ámbito menos productivo en todos los grupos de contraste, salvo en las mujeres del último curso universitario, donde realmente ocupa la primera posición relativa. Y, finalmente, tenemos al centro de interés 07 "La cocina y sus utensilios" que ocupa el decimoquinto lugar, excepto en el grupo femenino del primer y segundo curso donde alcanza el decimocuarto y decimotercer lugar, respectivamente.

También, los descriptores estadísticos en la tabla 3 dejan ver claramente unos centros de interés más o menos productivos, ya que podemos hablar de unos campos asociativos que se ubican entre los cinco primeros lugares en las tres submuestras (16 
"Profesiones y oficios", 10 “La ciudad", 14 "Los animales", 01 "Partes del cuerpo" y 08 "La escuela: muebles y materiales"); mientras que los retrasados, aparte de los mencionados, como se dijo anteriormente, son por este orden: 13 "Trabajos del campo y del jardín" y 02 “La ropa”.

Como puede comprobarse, el centro de interés 16 "Profesiones y oficios" es un campo de gran envergadura en los distintos subgrupos estudiados: todos los aprendices universitarios lo ubican en la primera y segunda posición. Asimismo, llaman la atención unos cambios en el interés que tienen los informantes de ambos sexos en algunos campos nocionales: 01 "Partes del cuerpo" muestra una bajada a nivel de rango desde el primer curso en el que se sitúa en quinta posición relativa entre ambos grupos (hombres $y$ mujeres), hasta el último curso, donde ocupa el primer puesto en los hombres y el tercer rango en las mujeres.

\begin{tabular}{|c|c|c|c|c|c|c|}
\cline { 2 - 8 } \multicolumn{1}{c|}{} & \multicolumn{3}{c}{ Correlación de variables: “sexo" y “curso académico" } \\
\cline { 2 - 8 } \multicolumn{1}{c|}{ C.I } & Hombre & Mujer & Hombre & Mujer & Hombre & Mujer \\
\hline 01 & 5 & 5 & 1 & 1 & 1 & 3 \\
\hline 02 & 13 & 13 & 12 & 12 & 11 & 13 \\
\hline 03 & 12 & 9 & 8 & 9 & 7 & 8 \\
\hline 04 & 11 & 10 & 11 & 8 & 14 & 14 \\
\hline 05 & 8 & 8 & 5 & 6 & 4 & 5 \\
\hline 06 & 17 & 16 & 16 & 16 & 16 & 1 \\
\hline 07 & 15 & 14 & 15 & 13 & 15 & 15 \\
\hline 08 & 4 & 3 & 7 & 5 & 6 & 7 \\
\hline 09 & 16 & 17 & 17 & 17 & 17 & 17 \\
\hline 10 & 2 & 2 & 3 & 4 & 3 & 4 \\
\hline 11 & 6 & 6 & 6 & 10 & 8 & 10 \\
\hline 12 & 10 & 12 & 9 & 11 & 9 & 11 \\
\hline 13 & 14 & 15 & 14 & 14 & 13 & 12 \\
\hline 14 & 3 & 4 & 4 & 3 & 5 & 6 \\
\hline 15 & 7 & 11 & 13 & 15 & 12 & 16 \\
\hline 16 & 1 & 1 & 2 & 2 & 2 & 2 \\
\hline 17 & 9 & 7 & 10 & 7 & 10 & 9 \\
\hline & & & & & & \\
\hline
\end{tabular}

Cuadro 4. Rango según el promedio de respuestas: correlación de las variables "sexo" y "curso académico" 


\subsubsection{Producción de vocablos}

Otro parámetro de gran relevancia para los estudios de disponibilidad léxica es el número total de vocablos que se actualizan en cada ámbito temático. Es de advertir que, en este sentido, un mayor número de vocablos no significa realmente una mayor riqueza léxica (vid. Samper Hernández 2009). Además, el número de informantes femeninas casi duplica al del grupo masculino, lo que realmente lleva a una desigualdad que no puede resolverse en términos de promedio, porque el resultado no reflejaría la cantidad de palabras que ha aportado cada muestreo. Por tanto, circunscribimos los datos comparativos a la posición relativa que ocupa cada campo asociativo en función de este parámetro.

En la tabla 5 se incorporan los datos estadísticos sobre la aportación de unidades diferentes. Se refleja la evolución del número de vocablos a través de los diferentes cursos según el factor "sexo". Se incluyen los totales de cada grupo por separado, con el objetivo de facilitar la comparación e interpretación de los datos obtenidos. También se adjunta un gráfico para ofrecer una visión clara de la disposición de los distintos campos nocionales en consonancia con el número de unidades léxicas.

\begin{tabular}{|c|c|c|c|c|c|c|}
\cline { 2 - 7 } \multicolumn{1}{c|}{} & \multicolumn{6}{c}{ Correlación de variables: “sexo” y “curso académico” } \\
\cline { 2 - 7 } \multicolumn{1}{c|}{ Curso1 } & \multicolumn{2}{c|}{ Curso 2 } & \multicolumn{2}{c|}{ Curso 3 } \\
\hline C.I & Hombre & Mujer & Hombre & Mujer & Hombre & Mujer \\
\hline 01 & 63 & 71 & 54 & 57 & 67 & 65 \\
\hline 02 & 55 & 77 & 48 & 56 & 61 & 56 \\
\hline 03 & 38 & 63 & 32 & 41 & 55 & 43 \\
\hline 04 & 77 & 95 & 62 & 77 & 61 & 59 \\
\hline 05 & 91 & 125 & 77 & 107 & 105 & 104 \\
\hline 06 & 47 & 56 & 33 & 47 & 59 & 53 \\
\hline 07 & 65 & 93 & 74 & 113 & 67 & 69 \\
\hline 08 & 99 & 125 & 79 & 86 & 83 & 82 \\
\hline 09 & 42 & 51 & 38 & 33 & 56 & 58 \\
\hline 10 & 153 & 195 & 137 & 156 & 143 & 147 \\
\hline 11 & 149 & 201 & 116 & 132 & 118 & 109 \\
\hline 12 & 45 & 36 & 36 & 33 & 39 & 36 \\
\hline 13 & 72 & 112 & 74 & 86 & 74 & 62 \\
\hline 14 & 89 & 105 & 71 & 84 & 79 & 93 \\
\hline 15 & 128 & 136 & 79 & 84 & 74 & 77 \\
\hline 16 & 171 & 221 & 119 & 145 & 139 & 124 \\
\hline 17 & 39 & 34 & 22 & 29 & 29 & 32 \\
\hline
\end{tabular}




\section{Totales \\ 1423 \\ 1796 \\ 1151 \\ 1366 \\ 1309 \\ 1269}

Cuadro 5. Total de vocablos: correlación de las variables "curso académico" y "sexo"

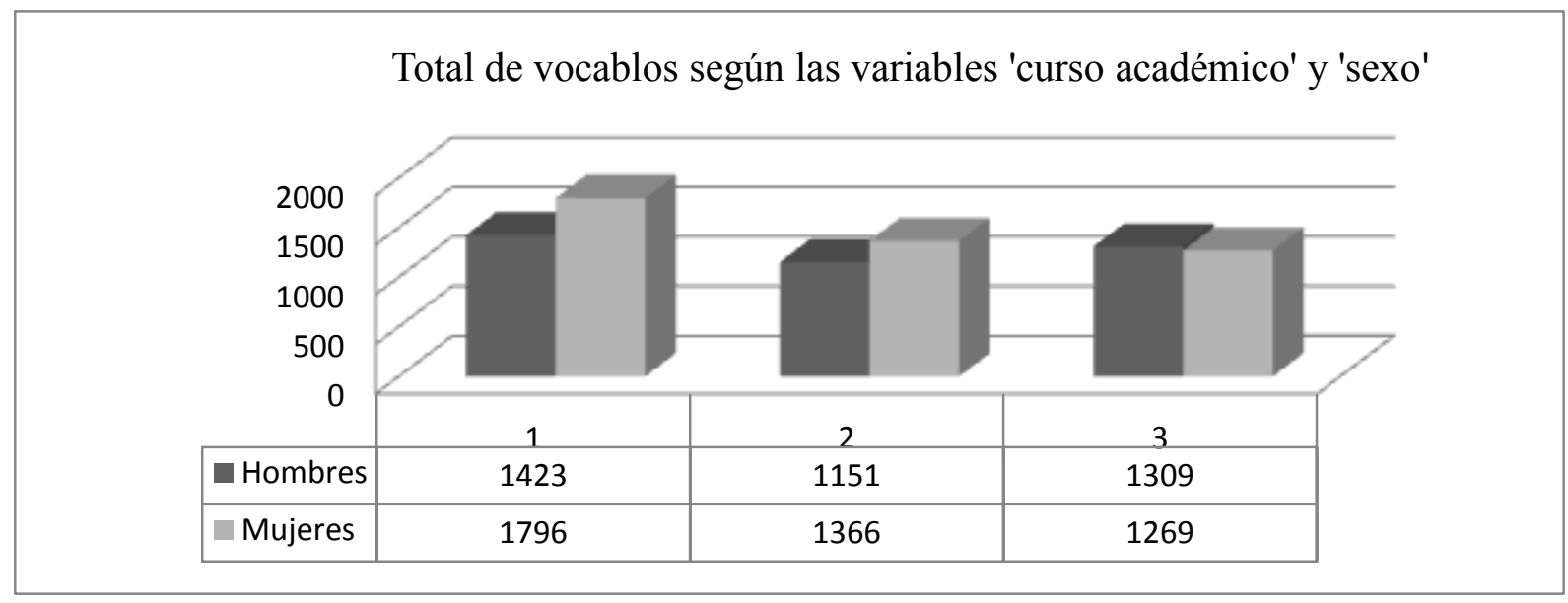

\section{Gráfico 11}

Lo primero que destaca en la tabla y el gráfico anteriores es la diferencia mostrada en la cantidad de vocablos aportados por unas y por otros, siempre a favor de las primeras. Aunque realmente podemos encontrar una respuesta en la disparidad registrada en la muestra entre hombres y mujeres, la superioridad masculina se mantiene esta vez en el último curso de formación universitaria, un curso académico en el que las mujeres representan una minoría 55 (49\%), frente a los hombres, que constituyen 57 (51\%).

Como puede vislumbrarse en los hombres del $3^{\circ}$ curso, los centros de interés 01 "Partes del cuerpo", 07 "La cocina y sus utensilios", 13 "Trabajos del campo y del jardín" y 15 "Juegos y distracciones" obtienen el mismo número de unidades diferentes. De ahí, el cotejo entre los tres subconjuntos de la tabla ofrece los resultados siguientes: los hombres del segundo y tercer curso incorporan un número idéntico de palabras en el centro de interés 13 "Trabajos del campo y del jardín" (74 vocablos); mientras que las mujeres lo han hecho también en el campo léxico 02 "La ropa" (56 vocablos). Por otro lado, las mujeres de ambos extremos de la tabla, es decir, entre las informantes del primer y tercer curso académico actualizan el mismo número de vocablos en el centro de interés 12 "Medios de transporte" (36 vocablos).

Con respecto a la progresión en la productividad léxica de nuestros informantes, también se ve una relación intrínseca con el número de sujetos que conforman cada grupo: las mujeres superan con creces al grupo contraste hasta llegar precisamente al último curso donde la evolución léxica es casi imperceptible. Los hombres, por otra parte, crecen menos que las mujeres, especialmente en el primer y segundo curso donde la diferencia muestral es mayor que la mitad - 31 hombres frente a 65 mujeres en el segundo curso y 43 hombres frente a 99 mujeres en el primer curso - en comparación 
con el último curso de formación universitaria donde, claro está, se percibe un número idéntico de informantes (57 varones frente a 55 de sexo femenino). En el cuadro 6, se observan algunas peculiaridades, que merecen ser destacadas, en lo tocante a la posición relativa de los distintos ámbitos temáticos.

\begin{tabular}{|c|c|c|c|c|c|c|}
\cline { 2 - 7 } \multicolumn{1}{c|}{} & \multicolumn{4}{c}{ Correlación de variables: “curso académico” y “sexo” } \\
\cline { 2 - 7 } \multicolumn{1}{c|}{ Curso 1 } & \multicolumn{2}{c|}{ Curso 2 } & \multicolumn{2}{c|}{ Curso 3 } \\
\hline C.1 & Hombre & Mujer & Hombre & Mujer & Hombre & Mujer \\
\hline 01 & 11 & 12 & 11 & 11 & 9 & 9 \\
\hline 02 & 12 & 11 & 12 & 12 & 12 & 13 \\
\hline 03 & 17 & 13 & 16 & 14 & 15 & 15 \\
\hline 04 & 8 & 9 & 10 & 10 & 11 & 11 \\
\hline 05 & 6 & 5 & 6 & 5 & 4 & 4 \\
\hline 06 & 13 & 14 & 15 & 13 & 13 & 14 \\
\hline 07 & 10 & 10 & 8 & 4 & 10 & 8 \\
\hline 08 & 5 & 6 & 5 & 6 & 5 & 6 \\
\hline 09 & 15 & 15 & 13 & 16 & 14 & 12 \\
\hline 10 & 2 & 3 & 1 & 1 & 1 & 1 \\
\hline 11 & 3 & 2 & 3 & 3 & 3 & 3 \\
\hline 12 & 14 & 16 & 14 & 15 & 16 & 16 \\
\hline 13 & 9 & 7 & 7 & 7 & 7 & 10 \\
\hline 14 & 7 & 8 & 9 & 8 & 6 & 5 \\
\hline 15 & 4 & 4 & 4 & 9 & 8 & 7 \\
\hline 16 & 1 & 1 & 2 & 2 & 2 & 2 \\
\hline 17 & 16 & 17 & 17 & 17 & 17 & 17 \\
\hline
\end{tabular}

Cuadro 6. Rango según el total de vocablos: correlación de las variables "curso académico" y "sexo"

A pesar de que se da una cierta equivalencia en la ordenación de los rangos en los tres estadios de formación universitaria, los ámbitos temáticos más y menos productivos no son coincidentes. En este caso, si vemos el número de vocablos por informante, destacan los centros de interés 16 "Profesiones y oficios", 10 "La ciudad", 11 "El campo", 15 "Juegos y distracciones" y 08 "La escuela: muebles y materiales". Esta convergencia no se da en los campos asociativos que menos unidades diferentes concentran: 17 "Los colores", 03 "Partes de la casa (sin muebles)", 12 "Medios de transporte" y 09 "Iluminación, calefacción y medios de airear un recinto". 
Como puede observarse, en los listados del sexo femenino al igual que el masculino del primer curso, el centro 16 "Profesiones y oficios" es el que más unidades diferentes recoge. En cambio, en los informantes del segundo y tercer curso es el centro de interés 10 "La ciudad" el que está encabezando la clasificación. Mayor coincidencia, digamos, se encuentra al hablar del campo léxico con menor número de vocablos: el 17 "Los colores" en el caso de las estudiantes del primer curso, del segundo y tercer curso de formación universitaria.

Destaca, asimismo, la diferencia en la posición relativa que ocupa el centro de interés 08 "La escuela: muebles y materiales" entre los tres estadios de formación universitaria, aunque la evolución mostrada no se produce de manera totalmente regular, superiores los rangos en los tres cursos en la relación femenina con la sexta posición. Algo similar, aunque en sentido opuesto, sucede en los rangos de los tres cursos que ocupan el quinto lugar en la gradación masculina. Ha de subrayarse, también, la coincidencia que se encuentra en el área temática 02 "La ropa" entre los resultados de los tres grupos de contraste: en ambos sexos de cada curso se pone de relieve la alternancia de rangos con uno de más o menos: el duodécimo lugar en la clasificación masculina frente al undécimo puesto en la femenina entre los encuestados del primer curso; mientras que esta equivalencia se distribuye de igual manera entre el segundo y tercer curso entre hombres y mujeres de ambos cursos aunque, en nuestro caso, con un rango de más a favor de las mujeres del tercer curso (decimotercer puesto).

\subsection{3. Índice de cohesión}

Los datos anteriormente mencionados podrían resultar apropiados para otro cálculo que informa sobre el índice de cohesión entre las aportaciones numéricas de nuestros informantes. También veremos el rango que ocupa cada centro de interés según este grado. Por consiguiente, un mayor número de encuestados implica que el índice de cohesión sea menor. Por tanto, si nos atenemos a lo que hemos dicho, es lógico que los hombres obtengan resultados más cohesionados que las mujeres, a excepción de las cifras conseguidas en el último curso, como puede verse en este cuadro:

\begin{tabular}{|c|c|c|c|c|c|c|}
\cline { 2 - 7 } \multicolumn{1}{c|}{} & \multicolumn{4}{c|}{ Correlación de variables: “curso académico" y “sexo” } \\
\cline { 2 - 7 } \multicolumn{1}{c|}{ Curso 1 } & \multicolumn{2}{c|}{ Curso 2 } & \multicolumn{2}{c|}{ Curso 3 } \\
\hline C.I & Hombre & Mujer & Hombre & Mujer & Hombre & Mujer \\
\hline 01 & 0,177 & 0,146 & 0,235 & 0,205 & 0,179 & 0,179 \\
\hline 02 & 0,134 & 0,086 & 0,150 & 0,114 & 0,103 & 0,114 \\
\hline
\end{tabular}




\begin{tabular}{|c|c|c|c|c|c|c|}
\hline 03 & 0,218 & 0,123 & 0,264 & 0,190 & 0,151 & 0,205 \\
\hline 04 & 0,112 & 0,082 & 0,130 & 0,104 & 0,090 & 0,105 \\
\hline 05 & 0,105 & 0,076 & 0,123 & 0,077 & 0,086 & 0,096 \\
\hline 06 & 0,114 & 0,094 & 0,148 & 0,104 & 0,092 & 0,253 \\
\hline 07 & 0,096 & 0,067 & 0,079 & 0,056 & 0,081 & 0,087 \\
\hline 08 & 0,114 & 0,088 & 0,109 & 0,106 & 0,107 & 0,117 \\
\hline 09 & 0,128 & 0,094 & 0,121 & 0,124 & 0,086 & 0,095 \\
\hline 10 & 0,082 & 0,059 & 0,085 & 0,065 & 0,073 & 0,076 \\
\hline 11 & 0,070 & 0,049 & 0,076 & 0,054 & 0,067 & 0,073 \\
\hline 12 & 0,204 & 0,194 & 0,228 & 0,212 & 0,201 & 0,192 \\
\hline 13 & 0,091 & 0,051 & 0,094 & 0,067 & 0,079 & 0,103 \\
\hline 14 & 0,133 & 0,103 & 0,155 & 0,123 & 0,112 & 0,104 \\
\hline 15 & 0,080 & 0,053 & 0,089 & 0,065 & 0,084 & 0,074 \\
\hline 16 & 0,095 & 0,065 & 0,106 & 0,075 & 0,077 & 0,101 \\
\hline 17 & 0,241 & 0,284 & 0,372 & 0,281 & 0,246 & 0,254 \\
\hline Medi & 0,129 & 0,101 & 0,151 & 0,119 & 0,113 & 0,131 \\
\hline$a$ & & & & & & \\
\hline
\end{tabular}

Cuadro 7. Grado de cohesión según las variables "curso académico" y "sexo" 


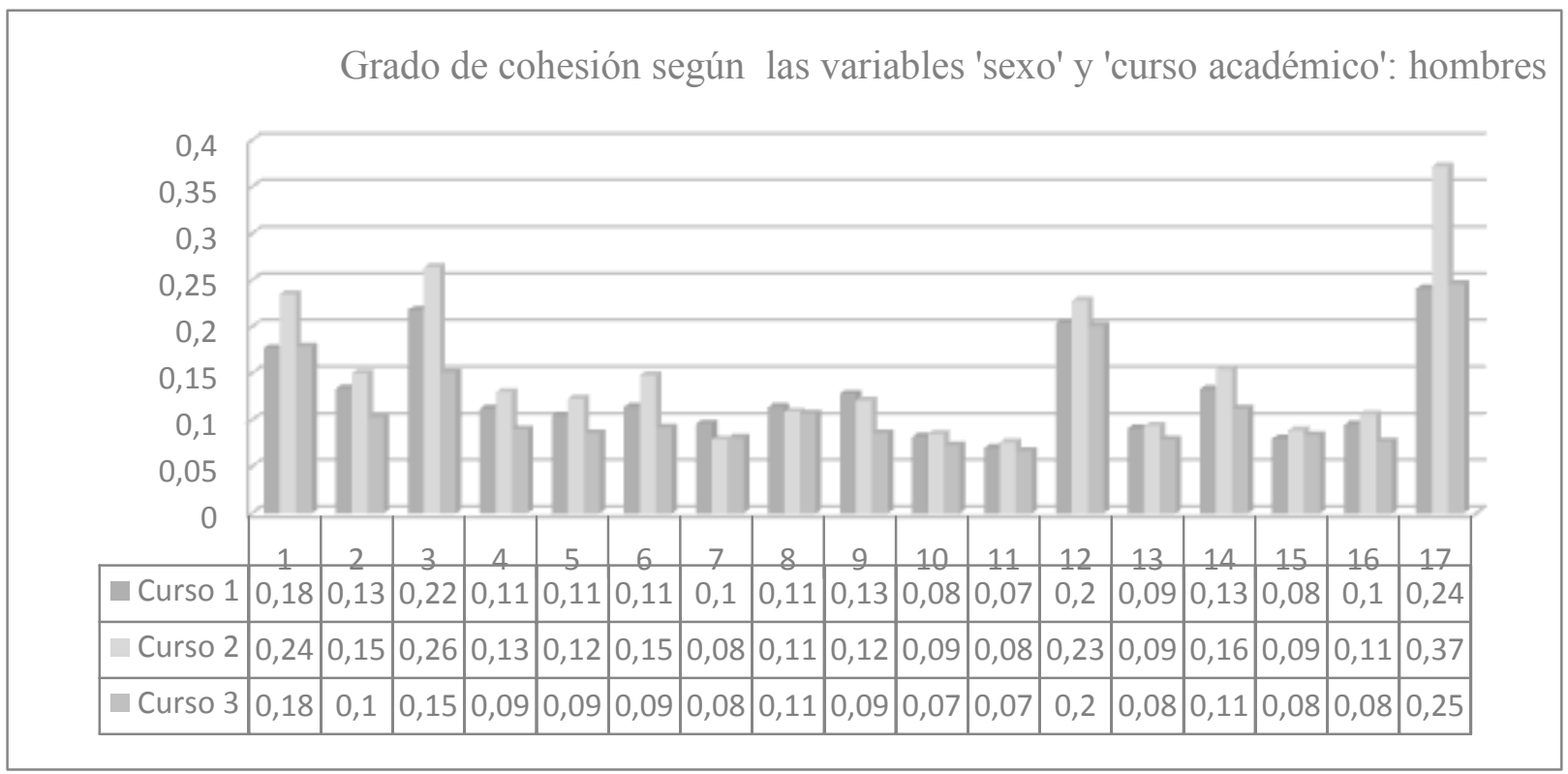

\section{Gráfico 12}

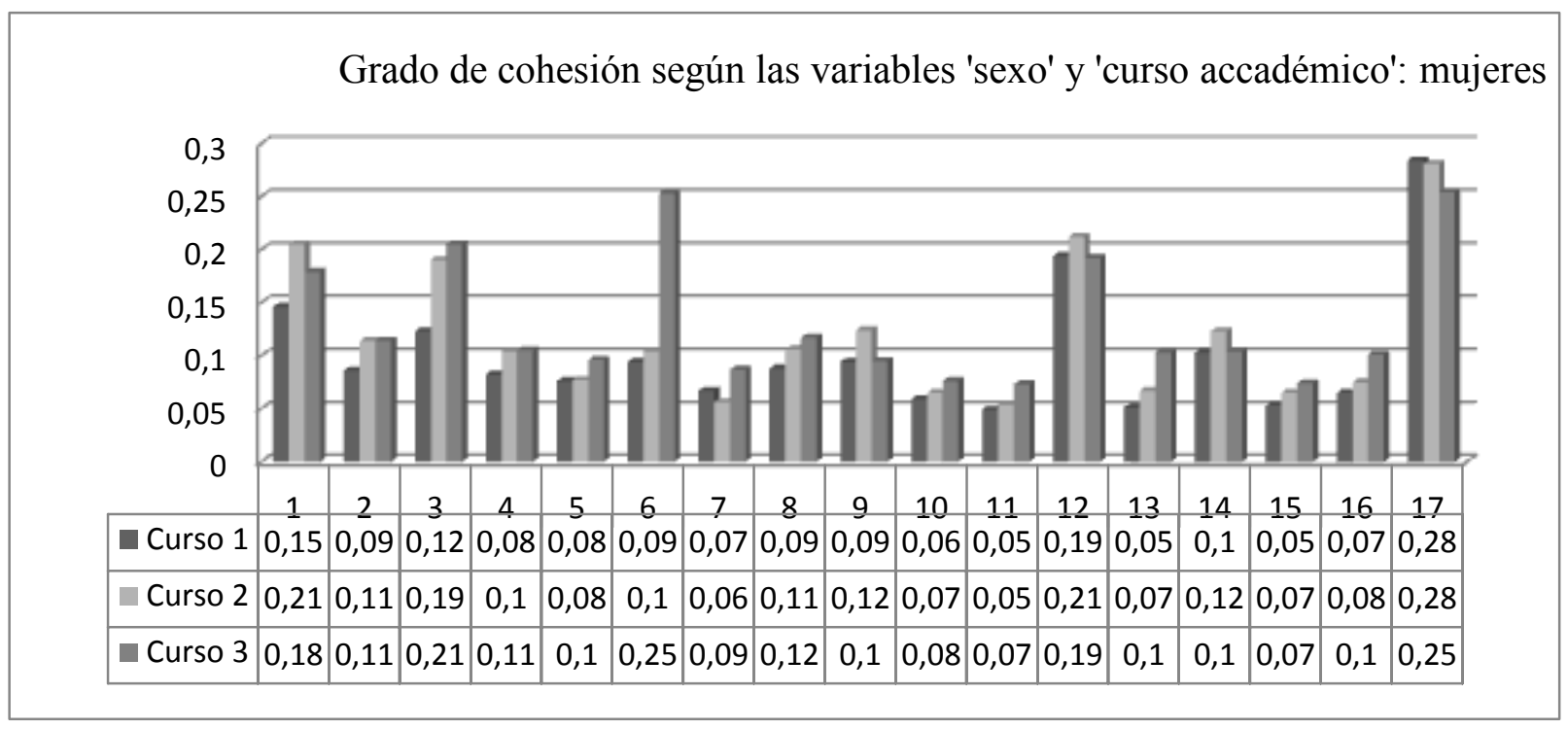

\section{Gráfico 13}

Los resultados muestran claramente que los hombres tienen un vocabulario claramente más cohesionado que las mujeres: esto ocurre obviamente en los cursos con menor número de informantes, sobre todo en el primer y segundo curso donde la cantidad de sujetos masculinos se reduce a la mitad en comparación con las informantes femeninas. 
No obstante, esta situación ha cambiado totalmente en el último curso de formación universitaria a favor de las mujeres. Ello supone una concreción semántica de las mujeres en todos los centros de interés, excepto en tres ámbitos temáticos como el 12 "Medios de transporte", el 14 "Los animales" y el 15 "Juegos y distracciones".

De este modo, hemos de subrayar la evolución que ostenta el rango del centro de interés 17 "Los colores", que en todas las columnas de los tres cursos cotejados termina ocupando la primera posición; mientras que en el centro de interés 11 "El campo", el menos productivo de todos los campos léxicos, los encuestados de los tres cursos de contraste coinciden en otorgarle el último lugar (vid. la tabla 8).

\begin{tabular}{|c|c|c|c|c|c|c|}
\cline { 2 - 7 } \multicolumn{1}{c|}{} & \multicolumn{6}{c|}{ Correlación de variables: “curso académico" y “sexo" } \\
\cline { 2 - 8 } \multicolumn{1}{c|}{ Curso 1 } & \multicolumn{2}{c|}{ Curso 2 } & \multicolumn{2}{c|}{ Curso 3 } \\
\hline C.I & Hombre & Mujer & Hombre & Mujer & Hombre & Mujer \\
\hline 01 & 4 & 3 & 4 & 3 & 3 & 5 \\
\hline 02 & 5 & 8 & 6 & 7 & 7 & 7 \\
\hline 03 & 2 & 4 & 2 & 4 & 4 & 3 \\
\hline 04 & 10 & 10 & 8 & 9 & 9 & 8 \\
\hline 05 & 11 & 11 & 9 & 11 & 10 & 12 \\
\hline 06 & 9 & 6 & 7 & 10 & 8 & 2 \\
\hline 07 & 12 & 12 & 15 & 16 & 13 & 14 \\
\hline 08 & 8 & 9 & 11 & 8 & 6 & 6 \\
\hline 09 & 7 & 7 & 10 & 5 & 11 & 13 \\
\hline 10 & 15 & 14 & 14 & 14 & 16 & 15 \\
\hline 11 & 17 & 17 & 17 & 17 & 17 & 17 \\
\hline 12 & 3 & 2 & 5 & 2 & 2 & 4 \\
\hline 13 & 14 & 16 & 16 & 13 & 14 & 10 \\
\hline 14 & 6 & 5 & 3 & 6 & 5 & 9 \\
\hline 15 & 16 & 15 & 13 & 15 & 12 & 16 \\
\hline 16 & 13 & 13 & 12 & 12 & 15 & 11 \\
\hline 17 & 1 & 1 & 1 & 1 & 1 & 1 \\
\hline
\end{tabular}

Cuadro 8. Rango del grado de cohesión según la correlación de las variables "curso académico" y "sexo"

Como puede comprobarse, la superioridad masculina se manifiesta sobre todo en los primeros cursos de formación universitaria. De hecho, los hombres del primer curso superan en dieciséis centros de interés al sexo femenino, salvo en 17 "Los colores" que está a favor de las mujeres. De la misma forma, en ningún caso las mujeres del segundo 
curso superen a los hombres, excepto en 09 "lluminación, calefacción y medios de airear un recinto" donde la diferencia apenas llega a sobrepasar un 0,003 de promedio.

En algunos centros de interés, los datos son parejos, ya que el índice de cohesión en 01 "Partes del cuerpo" del último curso de formación universitaria es 0,179 , es decir, los hombres igualan a las mujeres en este campo asociativo. En cuanto al centro de interés 09 "Iluminación, calefacción y medios de airear un recinto", los hombres del segundo curso se alejan cinco posiciones de las mujeres. Esto puede deberse al mayor número de unidades diferentes que obtenían los hombres en este centro. Los centros de interés tradicionalmente marcados por el rol social de ambos sexos obtienen la misma posición en los informantes del tercer curso, como en el campo nocional 02 "La ropa", O se diferencian mínimamente como en el centro de interés 07 "La cocina y sus utensilios", donde las mujeres se encuentran en una posición por encima de los hombres.

\section{Conclusiones}

En términos de promedio, los datos aportados por nuestros informantes muestran una cierta productividad léxica de los hombres, sobre todo en el primer y segundo curso (9,37 vs 8,54; 8,47 vs 7,73), pero no faltan ejemplos de centros de interés donde las mujeres superan a los hombres como en el caso del tercer curso de formación universitaria $(8,59$ vs 7,68). Ambos grupos de contraste en cada curso por separado muestran una relación entre ciertos centros de interés y el rol desempañado por hombres y mujeres, un dato de gran relevancia para la sociolingüística, porque los informantes siguen sus estudios en un mismo centro público de tipo mixto (vid. Samper Padilla y Samper Hernández 2006: 51).

Grosso modo, la superioridad que los hombres mostraban en el promedio de respuestas se ve claramente corroborada por el grado de cohesión semántica, que demuestra realmente que éstos tienen mayor homogeneidad de respuestas que las mujeres. Así, podemos confirmar que los centros de interés más cohesionados entre los tres cursos cotejados son los siguientes: 17 "Los colores", 12 "Medios de transporte", 01 "Partes del cuerpo", 03 "Partes de la casa (sin muebles)" y 04 "Objetos colocados en la mesa para la comida"; mientras que los que obtienen una menor concreción semántica son por este orden: 11 "El campo", 10 "La ciudad”, 15 “Juegos y distracciones", 16 "Profesiones y oficios" y 07 "La cocina y sus utensilios".

La correlación de las variables "sexo" y "curso académico" pone de relieve una divergencia marcada en los tres cursos académicos, por tanto, la distancia entre la competencia léxica de hombres y mujeres decrece en los tres cursos al pasar de un curso a otro. Estos resultados puedan encontrar explicación en factores de diversa índole, como la falta de motivación en el momento de rellenar las encuestas o como bien afirma Carcedo González (1998: 221), “El volumen medio de palabras que un informante 
produce depende del estímulo (centro de interés), ya que unos centros de interés pueden mostrar mucha riqueza léxica y otros muy pobre desarrollo léxico".

Entonces, no se corrobora nuestra hipótesis inicial sobre la graduación de la disponibilidad léxica en los estudiantes marroquíes de ELE, pues en contra de lo que esperábamos, no son los aprendientes del tercer curso los que más unidades léxicas incorporan en la mayoría de las áreas temáticas, porque en este último año universitario se produce un estancamiento en el crecimiento léxico de nuestros informantes (vid. Allueva Torres y Bueno García 2011; Hernández Muñoz 2015).

Además, hay que subrayar que en la mayoría de los estudios realizados sobre la producción léxica en niveles universitarios ha sido tratada en campos especializados (vid. Guerra Salas y Gómez Sánchez 2003; Urzúa, Echeverría y Sáez 2006; Navarro Marrero 2011, entre otros). Asimismo, ciertos estudios ponen de realce que es la intersección del sexo con factores sociales como la edad y el nivel sociocultural la que explica mejor las diferencias en dicho comportamiento lingüístico (vid. Gómez Molina 2006).

\section{BIBLIOGRAFÍA}

Ahumada, Ignacio. El léxico disponible de los estudiantes preuniversitarios de la provincia de Jaén. Jaén: Universidad de Jaén, 2006. Impreso.

Alba Ovalle, Orlando. Léxico disponible de la República Dominicana. Santiago de los Caballeros: Pontificia Universidad Católica Madre y Maestra, 1995. Impreso.

Allueva Torres, Pedro y Concepción Bueno García. "Estilos de aprendizaje y estilos de pensamiento en estudiantes universitarios. Aprender a aprender y aprender a pensar". Arbor: Ciencia, Pensamiento y Cultura, 187.3 (2011): 261-266. Impreso.

Arnal Purroy, María Luisa (coord.) et al. Léxico disponible de Aragón. Zaragoza: Libros Pórtico, 2004. Impreso.

Ayora Esteban, Carmen. Disponibilidad léxica en Ceuta: aspectos sociolingüísticos. Tesis doctoral. Sevilla: Universidad de Sevilla, 2003. Impreso.

- "Los estudios de disponibilidad léxica: ámbitos de aplicación". Cano López, Pablo (coord.), Actas del VI Congreso de Lingüística General, Santiago de Compostela, 3-7 de mayo de 2004, Madrid: Arco / Libros, vol. II, t. 2, 2007: 2367-2378. Impreso.

Bartol Hernández, José Antonio. Léxico disponible de Soria. Estudio y Diccionarios. Burgos: Instituto Castellano y Leonés de la Lengua, 2004. Impreso.

Bellón Fernández, Juan José. El léxico disponible de la provincia de Córdoba. Tesis doctoral. Las Palmas de Gran Canaria: Universidad de Las Palmas de Gran Canaria, 2003. Impreso. 
Benítez Pérez, Pedro. "Disponibilidad léxica en la zona metropolitana de Madrid". Boletín de la Academia Puertorriqueña de la Lengua Española (BAPLE) 1/1 (1992a): 71-102. Impreso.

- "Listas abiertas y listas cerradas de palabras en disponibilidad léxica". Actas del VIII Congreso Nacional de la Asociación Española de Lingüística Aplicada, Vigo: Universidad de Vigo, 1992b: 117-127. Impreso.

Carcedo González, Alberto. Disponibilidad léxica en español como lengua extranjera: el caso finlandés (estudio del nivel preuniversitario y cotejo con tres fases de adquisición). Turku: Universidad de Turku, 2000a. Impreso.

- "Índices léxico-estadísticos y graduación del vocabulario en la enseñanza de E/LE (aspectos culturales)". M. Franco et al. (eds.), Actas del X congreso de ASELE. Nuevas perspectivas en la enseñanza del español como lengua extranjera, Cádiz: Universidad de Cádiz, 2000b: 175-185. Impreso.

- Léxico disponible de Asturias. Vol. 1. Turku: Universidad de Turku, Publicaciones del Departamento de Lengua Española, Monografías, 2001. Impreso.

Casanova Ávalos, Manuela. "La disponibilidad léxica en la Comunidad Valenciana". José Luis Blas Arroyo, Manuela Casanova Ávalos y Mónica Velando Casanova (eds.), Discurso y sociedad: contribuciones al estudio de la lengua en contexto social. Castellón de la Plana: Universidad Jaume I, 2006: 737-751. Impreso.

Dimitríjevic, Naum R. Lexical availability. A new aspect of the lexical availability of secondary school children. Heidelberg: Julius Gross Verlag, 1969. Impreso.

Echeverría, Max S. et al. "Disponibilidad léxica en educación media". Revista de Lingüística Teórica y Aplicada, 25 (1987): 55-115. Impreso.

Etxebarría Arostegui, Maitena. “Disponibilidad léxica en escolares del País Vasco: variación sociolingüística y modelos de enseñanza bilingüe». Revista Española de Lingüística, 26/2 (1996): 301-326. Impreso.

Fernández-Merino Gutiérrez, Pablo Vicente. "Disponibilidad léxica de inmigrantes: diferencias cualitativas de la variable sexo". Yuko Morimoto, María Victoria Pavón Lucero y Rocío Santamaría Martínez (eds.), La enseñanza de ELE centrada en el alumno. La Rioja: Universidad Internacional de la Rioja, 2015: 341-356. Impreso.

Galloso Camacho, María Victoria. El léxico disponible de Ávila, Salamanca y Zamora. Burgos: Instituto Castellano y Leonés de la Lengua, 2003. Impreso.

Galloso Camacho, María Victoria y Josefina Prado Aragonés. "La estructura estadística del léxico disponible de informantes nativos e informantes de ELE». Castillo Carballo, María Auxiliadora, Olga Cruz Moya, Juan Manuel García Platero y Juan Pablo Mora Gutiérrez (coords.), Las gramáticas y los diccionarios en la enseñanza del español como segunda lengua: deseo y realidad. Actas del XV Congreso Internacional de ASELE, Sevilla: ASELE/Universidad de Sevilla, 2005: 370-375. Impreso. 
Gómez Devís, María Begoña. La disponibilidad léxica de los estudiantes preuniversitarios valencianos: reflexión metodológica, análisis sociolingüístico y aplicaciones. Valencia: Servicio de Publicaciones de la Universidad de Valencia, 2004. Impreso.

Gómez Molina, José Ramón y María Begoña Gómez Devís. La disponibilidad léxica de los estudiantes preuniversitarios valencianos. Estudio de estratificación sociolingüística. València: Universitat de València, 2004. Impreso.

Gómez Molina, José Ramón. "La variable 'sexo' en los estudios de disponibilidad léxica". Revista de Lingüística Teórica y Aplicada 44/1, (2006): 47-65. Impreso.

Gougenheim, Georges et al. L'élaboration du français fondamental. Étude sur l'établissement d'un vocabulaire et d'une grammaire de base. Paris: Didier, 1956. Imprimé.

Guerra Salas, Luis y María Elena Gómez Sánchez. “Español de los medios de comunicación: aspectos de disponibilidad léxica". Balmaseda Maestu Enrique (coord.), Actas del XIV Congreso Internacional de ASELE, Burgos: Universidad de Burgos, 2003: 356-371. Impreso.

Hernández Muñoz, Natividad. "La evaluación de la competencia léxica adulta: una aproximación a través de la disponibilidad léxica y la especialización académica en preuniversitarios". Revista de Filología de la Universidad de La Laguna, 33 (2015): 79-99. Impreso.

Lagüens Gracia, Víctor. "La variable sexo de los jóvenes aragoneses". María Luisa Arnal Purroy (ed.), Estudios de disponibilidad léxica en los jóvenes aragoneses. Zaragoza: Institución Fernando el Católico, 2008: 103-162. Impreso.

López Chávez, Juan et al. Colección de cuadernos de El léxico disponible de escolares mexicanos. 1. Léxico disponible de preescolares mexicanos (con Rosa María Mesa Canales). 2. Léxico disponible de primer grado de primaria (con María Trinidad Madrid Guillén). 3. Léxico disponible de segundo grado de primaria (con Martha Julián Peña). 4. Léxico disponible de tercer grado de primaria (con Rosalía Bolfeta Montes de Oca). 5. Léxico disponible de cuarto grado de primaria (con Marcela Flores Cervantes). 6. Léxico disponible de quinto grado de primaria (con Eva Núñez Alonso) y Léxico disponible de sexto grado de primaria. México: Editorial Alhambra Mexicana, 1993. Impreso.

López Chávez, Juan. “Comportamiento sintáctico de algunos verbos ordenados según su grado de disponibilidad léxica". Revista de Estudios de Adquisición de la Lengua Española (REALE), 1 (1994): 67-84. Impreso.

López Morales, Humberto. "Disponibilidad léxica y estratificación socioeconómica". Dialectología y Sociolingüística. Temas Puertorriqueños. Madrid: Hispanova de Ediciones, 1979: 173-181. Impreso.

Lugones Hoya, Ana. "El léxico disponible de los alumnos de secundaria bilingüe (españolinglés) en Salamanca». Tesis doctoral. Universidad de Salamanca, 2015. Repositorio documental Gredos. Web. 24 Sep. 2017. 
Mackey, William Francis. Le vocabulaire disponible du Français. 2 volumes. ParisBruxelles-Montréal: Didier, 1971. Imprimé.

Mateo García, María Victoria. “Disponibilidad léxica en el C.O.U. almeriense. Estudio de estratificación social". Tesis doctoral. Universidad de Almería, 1998. DIGIBUG: Repositorio institucional de la Universidad de Granada. Web. 06 Oct. 2017.

Michéa, René. “Vocabularie et culture”. Les langues modernes, 44 (1950): 188-189. Imprimé.

Navarro Marrero, Yanira. Léxico disponible específico de los estudiantes de fisioterapia en la Universidad de Salamanca. Tesina de grado. Salamanca: Universidad de Salamanca, 2011. Impreso.

Pérez Serrano, Mercedes. Estudio de disponibilidad léxica en estudiantes de E/LE en los centros de interés 'Medios de transporte' y 'Profesiones y oficios' (memoria de máster). Instituto Cervantes: Universidad Internacional Menéndez Pelayo, 2009. Impreso.

Prado Aragonés, Josefina y María Victoria Galloso Camacho. "La variable sexo en el léxico disponible de alumnos de Primaria y Secundaria de Huelva". José Luis Blas Arroyo et al. (eds.), Discurso y sociedad II. Nuevas contribuciones al estudio de la lengua en contexto social. Castellón de la Plana: Universitat Jaume I, 2008: 583595. Impreso.

Ruíz Basto, Araceli. Disponibilidad léxica de los alumnos de primer ingreso en el colegio de Ciencias y Humanidades Plantel Naucalpan. México D. F.: Universidad Autónoma de México, 1987. Impreso.

Samper Hernández, Marta. Disponibilidad léxica en alumnos de español como lengua extranjera. Málaga: ASELE, 2002. Impreso.

- Evolución de la disponibilidad léxica en estudiantes grancanarios de enseñanza primaria y secundaria. Tesis doctoral. Salamanca: Universidad de Salamanca, 2003. Impreso.

- Evolución de la disponibilidad léxica en estudiantes grancanarios de enseñanza primaria y secundaria. Las Palmas de Gran Canaria: Cabildo de Gran Canaria, 2009. Impreso.

Samper Padilla, José Antonio y Clara Eugenia Hernández Cabrera. “Disponibilidad léxica en Las Palmas: análisis cuantitativo", Rodríguez Fonseca y Vázquez (eds.), Actas del IIl Seminario Internacional sobre "Aportes de la lingüística a la enseñanza de la lengua materna”, Carolina: Universidad de Puerto Rico, 1995. Impreso.

-. "El estudio de la disponibilidad léxica en Gran Canaria: datos iniciales y variación sociolingüística". Manuel Almeida y Josefa Dorta (eds.), Contribuciones al estudio de la lingüistica hispánica. Homenaje al profesor Ramón Trujillo Carreño. Tomo II. La Laguna: Universidad de la Laguna, 1997: 229-239. Impreso.

Samper Padilla, José Antonio. "Criterios de edición del léxico disponible: sugerencias". Lingüística, 10 (1998): 311-333. Impreso. 
Samper Padilla, José Antonio et al. “El proyecto de estudio de la disponibilidad léxica en español". Raúl Ávila, José Antonio Samper Padilla, Hiroto Ueda et al. Pautas y pistas en el análisis del léxico hispano(americano). Frankfurt-Madrid: VervuertIberoamericana, 2003: 27-140. Impreso.

Samper Padilla, José Antonio y Marta Samper Hernández. "Aportaciones recientes de los estudios de disponibilidad léxica". Lynx. Panorámica de Estudios Lingüísticos, 5 (2006): 5-95. Impreso.

Sandu, Bianca. "La disponibilidad léxica en alumnos rumanos de ELE: incidencia de la variable 'sexo/género' y su correlación con el "nivel escolar".. Lingua Americana, 31 (2012): 61-85. Serbiluz. Web. 13 Nov. 2017.

- "Léxico disponible de alumnos rumanos que aprenden español como lengua extranjera en centros escolares bilingües rumano-españoles". Tesis doctoral. Universidad de Las Palmas de Gran Canaria, 2014. ACCEDA: Documentación científica de la ULPGC en abierto. Web. 29 Dic. 2017.

Serfati, Mohamed. Disponibilidad léxica en alumnos marroquíes de español como lengua extranjera (nivel universitario) (Memoria de máster). Agadir: Universidad Ibn Zohr, 2010. Impreso.

- "La ropa, alimentos y bebidas en el léxico disponible de estudiantes marroquíes de nivel universitario", Celma Valero, María Pilar, María Jesús Gómez del Castillo y Carmen Morán Rodríguez (eds.), Actas del L Congreso Internacional de la AEPE (Asociación Europea de Profesores de Español), Burgos: Universidad Isabel I de Castilla, 2015: 490-501. Impreso.

-. "La disponibilidad léxica de estudiantes marroquíes de nivel universitario: resultados generales". Philologica Canariensia, 22 (2016): 105-116. Impreso.

- "Cálculo de disponibilidad léxica en ELE de universitarios marroquíes de Agadir: el programa Lexidisp". Actas del I Congreso de español como lengua extranjera del Magreb del Instituto Cervantes de Rabat (2015), Rabat: Publicaciones del Instituto Cervantes (Marruecos), 2017a: 111-117. Alicante: Centro Virtual Cervantes. Web. 15 Jun. 2017.

- . "Incidencia cuantitativa de la variable 'curso académico' en léxico disponible de estudiantes marroquíes de español como lengua extranjera (nivel universitario)". Aljamía. Revista de la Consejería de Educación en Marruecos, 28 (2017b): 35-54. Web. 28 Ago. 2017.

- "Incidencia cuantitativa del factor 'lengua materna' en la disponibilidad léxica de estudiantes marroquíes de Español como Lengua Extranjera (nivel universitario)". Estudios Interlingüísticos, 5 (2017c): 121-145. Web. 18 Sep. 2017.

Serfati, Mohamed y Lahoussine Aabidi. Disponibilidad léxica de ELE en Marruecos (niveles de Secundaria y Enseñanza Superior en la región Souss Massa Drâa). Agadir: Facultad de Letras y Ciencias Humanas - Universidad Ibn Zohr, 2013. Impreso. 
Urzúa, Paula et al. "Disponibilidad léxica matemática. Análisis cuantitativo y cualitativo”. RLA. Revista de Lingüistica Teórica y Aplicada, 44 (2) (2006): 59-76. Impreso.

Valencia, Alba y Max S. Echeverría. Disponibilidad léxica en estudiantes chilenos. Santiago de Chile: Universidad de Chile-Universidad de Concepción, 1999. Impreso.

Fecha de recepción: 28 de diciembre de 2017. Fecha de aceptación: 12 de abril de 2018. 